\title{
A PHYSICAL AND PSYCHIATRIC EVALUATION OF YOUNG FEMALES WITH SUICIDAL ATTEMPTS WITH SPECIAL REFERENCE TO THYROID PROFILE AND PCOS
}

\author{
Hariom Gupta ${ }^{1}$, Shailendra Kumar Manjhvar², Nimisha Mishra ${ }^{3}$, Ajit Kumar Jain ${ }^{4}$, Manoj Indurkar ${ }^{5}$ \\ ${ }^{1}$ Associate Professor, Department of Medicine, Sanjay Gandhi Memorial Hospital \& Shyam Shah Medical College, Rewa. \\ ${ }^{2}$ Associate Professor, Department of Medicine, Sanjay Gandhi Memorial Hospital \& Shyam Shah Medical College, Rewa. \\ ${ }^{3}$ Associate Professor, Department of Psychiatry, Sanjay Gandhi Memorial Hospital \& Shyam Shah Medical College, Rewa. \\ ${ }^{4}$ Postgraduate Student, Department of Medicine, Sanjay Gandhi Memorial Hospital \& Shyam Shah Medical College, Rewa. \\ 5 Professor and HOD, Department of Medicine, Sanjay Gandhi Memorial Hospital \& Shyam Shah Medical College, Rewa.
}

\begin{abstract}
BACKGROUND

The objective of this study is to overview the attempts of suicide in young females and its relation to PCOS and thyroid profile dysfunction. World health report puts that the yearly global prevalence of suicide attempt varies between $2 \%$ to $20 \%{ }^{1}$ The incidence of attempted suicide is greatly influenced by the differences in age, sex, race, religion, culture, marital status, habitat, climate and social systems. ${ }^{2}$ This study aimed to analyse risk factor, mode of attempt, and spectrum association with PCOS, thyroid dysfunction in young females.
\end{abstract}

\section{MATERIALS AND METHODS}

The present study was conducted in department of medicine with history of attempted suicides from March 2015 to May 2016 (100 cases). All female (15-49 years) subjects meeting the selection criteria were evaluated.

\section{RESULTS}

There were a total of 738 female patients admitted in the Emergency ward of our tertiary care centre during the study period of one and half years from 1st March 2015 till 31st May 2016. During this study period, 100 patients of attempt of suicide who were admitted to the Medical ICU of our tertiary care centre were studied. This resulted in a prevalence of $8.9 \%$, and incidence of attempt of suicides were $96 \%$ cases of poisoning out of which $27 \%$ were unmarried and $69 \%$ were married females and the rest $4 \%$ by hanging with $2 \%$ each. Evaluation of hospitalised patients due to suicidal attempt showed PCOS in $14 \%$ cases and Hypothyroidism and Hyperthyroidism in 16\% and 1\% cases respectively. Among cases with Hypothyroidism, signs of depression were present in $81 \%$ cases $(n=13)$ whereas $19 \%$ cases $(n=3)$ had stress. Signs of frustration, anxiety, stress \& depression were present in 7\%, 7\%, 29\% and 57\% cases respectively among those diagnosed to have PCOS. Overall, there were $58 \%$ cases of stress which led to suicidal attempt.

\section{CONCLUSION}

Present study revealed importance of hormonal changes which occur in PCOS, hypothyroidism and causes psychophysical changes in young and reproductively active females. An attempt is made to focus on all these issues so that in future we can intervene early and prevent complications.

\section{KEYWORDS}

Young Female, PCOS, Thyroid Hormone Related Dysfunction.

HOW TO CITE THIS ARTICLE: Gupta H, Manjhvar SK, Mishra N, et al. A physical and psychiatric evaluation of young females with suicidal attempts with special reference to thyroid profile and PCOS. J. Evolution Med. Dent. Sci. 2017;6(14):1103-1106, DOI: $10.14260 /$ Jemds/2017/239

\section{BACKGROUND}

The word suicide is derived from Latin word sui and caedere means to kill one self. It is purposely ending one's own life. A suicide attempt is defined as "self-destructive behaviour with inferred or explicit intent to die." 3 Suicidal behaviour is a highly complex human behaviour and is known to mankind since antiquity. Suicidal behaviour ranges from suicidal thought to completed suicide. ${ }^{2}$

Financial or Other, Competing Interest: None.

Submission 08-01-2017, Peer Review 01-02-2017,

Acceptance 07-02-2017, Published 16-02-2017.

Corresponding Author:

Dr. Hariom Gupta,

Doctors Colony,

S. S. Medical College,

Rewa-486001.

E-mail: guptadr.hariom@yahoo.co.in

DOI: $10.14260 /$ jemds $/ 2017 / 239$
Today, suicide attempt has become a major social problem, not only for developed countries but also for developing countries. Nearly four lakh people every year commit suicide around the world. Suicide is the tenth leading cause of death for all ages in the most of the countries. ${ }^{4}$

The risk factors for suicidal attempt include disorders like depression, schizophrenia, OCD, personality disorder, phobic disorder, post-traumatic stress disorder, dementia, substance abuse alcohol, cocaine, etc. In addition to mental disorder, stress is also a major risk factor of suicide. ${ }^{5}$

This voluntary attempt at the tragedy of self-inflicted death has always attracted the attention of the medical as well as the legal fraternity. Although it is quite obvious that one has to 'attempt' suicide in order to 'commit' it, it could be held that the event of attempting suicide need not always have death as its objective.

Attempted suicide is the problem of major concern in today's society, which sometimes or the other affects the lives 
of a significant proportion of the population. The factors implicated in the attempt to suicide includes age, sex, race, religion, culture, marital status, habitat, climate and social systems.

Suicidal behaviour required an integrated and in-depth exploration in light of prevailing biophysical sociocultural frame. This study aimed to analyse risk factors, mode of attempt of suicide, and spectrum association with PCOS, Thyroid Profile Dysfunction in young females considering attempted suicide as a major health problem in this subgroup of population.

\section{MATERIALS AND METHODS}

All female (15-49 years) subjects with the selection criteria were evaluated with the help of a semi-structured proforma consisting of sociodemographic and clinical variables, age, education level, living standers, socioeconomic level, smoking, and illegal substance use. Information about previous suicide attempts, family history of suicide, psychiatric disorders, pre-morbid personality traits, internal family problems, precipitating factors, and suicide methods were obtained by parental and patients' interviews. A detailed general, physical, systemic examination and relevant investigations like abdominal sonography, thyroid function test was done. Mental disorder diagnosis made as per ICD-10 criteria. Severity of co-existing psychiatric disorders and stress were evaluated with corresponding scales.

\section{OBSERVATIONS AND RESULTS}

In our study, mean age for attempt of suicide was 25.5+7.6, but majority of the victims (41\%) were in their third decade of life followed by those in fourth decade (30\%).

\begin{tabular}{|c|c|}
\hline Age & Present Study \\
\hline $15-19$ & $25 \%$ \\
\hline $20-29$ & $41 \%$ \\
\hline $30-39$ & $30 \%$ \\
\hline $40-49$ & $4 \%$ \\
\hline Table 1. Age Group of Presentation of Attempt of Suicide \\
\hline
\end{tabular}

The above table reveals that more number of attempts of suicide was found in the age group of 20-29 years (41.0\%) followed by $30-39$ years (30\%), $15-19$ years (25\%) and $40-49$ years $(4 \%)$.

\begin{tabular}{|c|c|c|c|c|c|}
\hline Living in & \multicolumn{2}{|c|}{$\begin{array}{c}\text { Urban } \\
n=75\end{array}$} & \multicolumn{2}{|c|}{$\begin{array}{l}\text { Rural } \\
n=25\end{array}$} & $\begin{array}{c}\text { Total } \\
(p>0.05)\end{array}$ \\
\hline Unmarried & 24 & $83 \%$ & 5 & $17 \%$ & 29 \\
\hline Married & 51 & $72 \%$ & 20 & $28 \%$ & 71 \\
\hline Total & \multicolumn{2}{|c|}{75} & \multicolumn{2}{|c|}{25} & 100 \\
\hline
\end{tabular}

$\mathrm{P}$ value is 0.3731 , Chi-square statistic $=0.7933$. Majority of females $(75 \%)$ belonged to urban area of which most of them $(83 \%)$ were unmarried. However, domicile was not a significant ( $p$ 0.37) indicator for attempt of suicide.

\begin{tabular}{|c|c|c|}
\hline Socioeconomic Class & $\mathbf{n}$ & Incidence \\
\hline Upper (I) & 5 & $5 \%$ \\
\hline Upper Middle (II) & 15 & $15 \%$ \\
\hline Middle/Lower-middle(III) & 60 & $60 \%$ \\
\hline Lower/Upper lower (IV) & 10 & $10 \%$ \\
\hline Lower (V) & 10 & $10 \%$ \\
\hline Total & $\mathbf{1 0 0}$ & $\mathbf{1 0 0} \%$ \\
\hline
\end{tabular}

Table 3. Shows Correlation of Socioeconomic Status and Attempt of Suicide

The above table reveals that majority of the patients were from low income group (70\%), rest $20 \%$ and $10 \%$ belong to upper and lower groups respectively.

\begin{tabular}{|c|c|c|c|c|c|}
\hline Education & \multicolumn{2}{|c|}{ Unmarried } & \multicolumn{2}{|c|}{ Married } & $\begin{array}{c}\text { Present Study } \\
(\mathbf{p}<\mathbf{0 . 0 5})\end{array}$ \\
\hline Illiterate & 10 & $35 \%$ & 37 & $52 \%$ & 47 \\
\hline PRI. To SEC. & 15 & $51 \%$ & 15 & $45.5 \%$ & 48 \\
\hline $\begin{array}{c}\text { GRA. To Post } \\
\text { GRA. }\end{array}$ & 04 & $14 \%$ & 01 & $1.5 \%$ & 5 \\
\hline Total & \multicolumn{2}{|c|}{$\mathbf{2 9}$} & \multicolumn{2}{|c|}{$\mathbf{7 1}$} & $\mathbf{1 0 0}$ \\
\hline \multicolumn{4}{|c|}{$\begin{array}{c}\text { Table 4hows Correlation of Literacy } \\
\text { and Attempt of Suicide }\end{array}$} \\
\hline
\end{tabular}

P value is 0.0036 , Chi-square: 11.250 .

The above table reveals that $47 \%$ patients who attempted suicide had no formal education, $48 \%$ were high school literates and the proportion went down to 5\% among graduates and postgraduates implying significant differences $(p<0.01)$ in the education level and suicidal attempt.

\begin{tabular}{|c|c|c|c|c|c|}
\hline Mode & \multicolumn{2}{|c|}{ Unmarried } & \multicolumn{2}{c|}{ Married } & $\begin{array}{c}\text { Total } \\
(\mathbf{p}>\mathbf{0 . 0 5})\end{array}$ \\
\hline Rat poison & 13 & $45 \%$ & 35 & $51 \%$ & 48 \\
\hline OPP & 07 & $24 \%$ & 12 & $16.5 \%$ & 19 \\
\hline Unknown & 03 & $10 \%$ & 14 & $18 \%$ & 17 \\
\hline Kaner seed & 01 & $3.5 \%$ & 05 & $07 \%$ & 06 \\
\hline Hanging & 02 & $07 \%$ & 02 & $03 \%$ & 04 \\
\hline Celphos & 01 & $3.5 \%$ & 02 & $03 \%$ & 03 \\
\hline Datura Fruit & 00 & 00 & 01 & $1.5 \%$ & 01 \\
\hline $\begin{array}{c}\text { Alprazolam } \\
\text { tab. }\end{array}$ & 01 & $3.5 \%$ & 00 & 00 & 01 \\
\hline $\begin{array}{c}\text { Ergotamine } \\
\text { tab }\end{array}$ & 01 & $3.5 \%$ & 00 & 00 & 01 \\
\hline Total & \multicolumn{5}{|c|}{ 29 } \\
\hline \multicolumn{6}{|c|}{ Table 5. Shows Correlation of } \\
\hline
\end{tabular}

$\mathrm{P}$ value is 0.4001 , Chi-square: 8.350 . The above table reveals that there are $96 \%$ cases of poisoning out of which $27 \%$ were unmarried and $69 \%$ were married females the rest $4 \%$ by hanging with $2 \%$ each. Among the cases of poisoning most common was rat poison which is $48 \%$, and second most common is organophosphate $19 \%$, others are Kaner $6 \%$, Celphos 3\%, and least common are Datura, Alprazolam, Ergotamine, each constituting $1 \%$. 
correlation with PCOS, Hypothyroidism and Stress causes cofactor for attempt of suicide

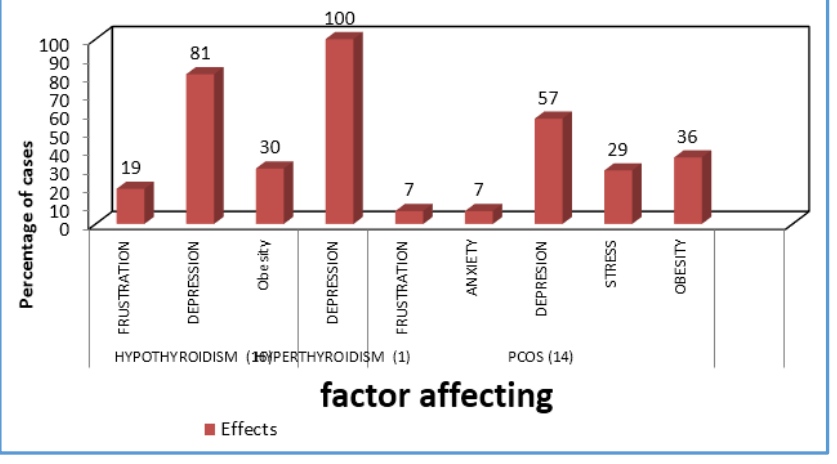

Figure 1

\begin{tabular}{|c|c|c|c|c|c|}
\hline Mode & \multicolumn{2}{|c|}{$\begin{array}{l}\text { 15-24 Age } \\
\text { Group }\end{array}$} & \multicolumn{2}{|c|}{$\begin{array}{l}\text { 25-49 Age } \\
\text { Group }\end{array}$} & \multirow{2}{*}{$\begin{array}{c}\begin{array}{c}\text { Total } \\
(\mathbf{p}>\mathbf{0 . 0 5})\end{array} \\
96\end{array}$} \\
\hline Poisoning & 41 & $43 \%$ & 55 & $57 \%$ & \\
\hline Hanging & 04 & $100 \%$ & 00 & 00 & 04 \\
\hline Total & \multicolumn{2}{|c|}{45} & \multicolumn{2}{|c|}{55} & 100 \\
\hline \multicolumn{6}{|c|}{$\begin{array}{c}\text { Table 6. Shows Correlation with Mode } \\
\text { of Attempt of Suicide and Age Group }\end{array}$} \\
\hline
\end{tabular}

$\mathrm{P}$ value is 0.0812 , Chi-square statistic $=3.041$. The above table reveals that poisoning is the primary mode of attempt in most of the patients (96\%). However, this does not have a significant bearing $(p>0.05)$ on the age group of patients who had attempted suicide.

\begin{tabular}{|c|c|c|c|}
\hline $\begin{array}{c}\text { Hormonal Profile } \\
\text { Dysfunction }\end{array}$ & \multicolumn{2}{|c|}{ Effects } & $\begin{array}{c}\text { Present } \\
\text { study }\end{array}$ \\
\hline \multirow{3}{*}{ Hypothyroidism (16) } & Frustration & 3 & $19 \%$ \\
\cline { 2 - 4 } & Depression & 13 & $81 \%$ \\
\cline { 2 - 4 } & Obesity & 5 & $30 \%$ \\
\hline Hyperthyroidism (1) & Depression & 1 & $100 \%$ \\
\hline \multirow{4}{*}{ PCOS (14) } & Frustration & 1 & $07 \%$ \\
\cline { 2 - 4 } & Anxiety & 1 & $07 \%$ \\
\cline { 2 - 4 } & Depression & 8 & $57 \%$ \\
\cline { 2 - 4 } & Stress & 4 & $29 \%$ \\
\cline { 2 - 4 } & Obesity & 5 & $36 \%$ \\
\hline \multirow{3}{*}{ Table 7. Shows effects of Thyroid Dysfunction and PCOS } \\
leading to Attempt of Suicide \\
\hline
\end{tabular}

The above table reveals that Depression is present in majority of patients- $81 \%$ with hypothyroidism, $100 \%$ in hyperthyroidism and $57 \%$ with PCOS. Among the latter, obesity and stress was present in $36 \%$ and $29 \%$ patients respectively.

\begin{tabular}{|c|c|c|}
\hline Sl. No. & Precipitating Factor & Present Study \\
\hline 1 & Intimate partner & $40 \%$ \\
\hline 2 & Financial problem & $25 \%$ \\
\hline 3 & Recent crisis & $20 \%$ \\
\hline 4 & Problem at work & $10 \%$ \\
\hline 5 & Physical health & $5 \%$ \\
\hline \multicolumn{3}{|c|}{$\begin{array}{c}\text { Table 8. Precipitating Factors Commonly } \\
\text { Associated with Attempt of Suicide }\end{array}$} \\
\hline
\end{tabular}

The above table reveals that intimate partner $(40 \%)$ is the most commonly associated problem in social life, followed by financial issues $(25 \%)$ and recent crisis, problem at work, physical health $20 \%, 10 \%, 5 \%$ respectively.

\section{DISCUSSION}

The present study was carried out in patients admitted in Department of Medicine, S.S. Medical College and associated S. G. M. H, Rewa (M. P.) from March 2015 to May 2016. 100 patients of attempted suicide admitted to the emergency department during the study period were studied. A total 738 female patients of age 15-49 years presented with complaints of attempted suicide by various modes of attempts like poisoning, hanging and drowning. This study showed female predominance with females constituting $54.5 \%$ of the total cases. This is in contrast to study by Jain et al (2011) which showed male dominance (56\%). ${ }^{6}$ In our study, mean age for attempt of suicide was found out to be $25.5+7.6$ years, a finding similar to study by Jain et al (2011) where mean age at suicide attempt was 31.5 years. In Narang et al ${ }^{7}$ study from Ludhiana, majority (71\%) of suicides in India were by persons below the age of 44 years. Urban dwellers constituted $75 \%$ of the study sample including unmarried females $24 \%$, married females 51\%. Parkar et al (2009) found that marital problems contributed significantly in suicide and suicide attempts in the urban slum of Mumbai, India. ${ }^{9}$ Subjects from lower middle class attempted suicide more often $(70 \%)$, followed by subjects from upper socioeconomic status (20\%). Preti and Miotto (1999) also confirm the link between the economic status of people and suicide. ${ }^{10} 85 \%$ of the victims lived in nuclear families against $15 \%$ who lived in extended nuclear families in contrast to study by Jain et al (2011) which showed $41 \%$ attempters belonging to nuclear family. 6

In our study, $95 \%$ females were either illiterate or educated up to secondary school in contrast to the finding in the study by Jain et al (2011) where $63 \%$ were educated up to matriculation or beyond.

Married females (71\%) have outnumbered the unmarried ones (29\%). Majority (71\%) of suicides in India are by persons below the age of 44 years which imposes a huge social, emotional and economic burden in a study from Ludhiana by Narang et al. ${ }^{7}$

In our study, Housewives (46\%) topped the list followed by manual labourers (29\%) and students (25\%). Panda B.B. et al (2015) found attempted suicide in the proportion asHousewives $20 \%$, followed by Manual labour 23\%, and students $21 \% .10$

Poisoning (34.8\%), Hanging (31.7\%) and Self-immolation $(8.5 \%)$ were the common methods used to commit suicide.

Similar observation was noted by Farzaneh et al (2010), which observes self-poisoning as the most common nature of suicide associated with students in Tehran, Iran. ${ }^{12}$

During hospitalisation, in cases of attempt of suicide, on further evaluation shows 14\% PCOS, 16\% Hypothyroidism and $1 \%$ Hyperthyroidism.

According to Etsenbruch's \& Benson's study ${ }^{12}$ (2006), PCOS was leading to frustration in $67 \%$, anxiety in $16 \%$, stress in $10 \%$, obesity in $50 \%$ cases, but depression according to Bhattacharya study (2010) ${ }^{13}$ is $5 \%$, in contrast to our study which led to frustration in $7 \%$, anxiety in $7 \%$, stress in $29 \%$, depression in $57 \%$ cases. 
It is found that in case of Hypothyroidism according to Bartalena (1990) ${ }^{14}$ study, depression was present in $32 \%$ patients unlike our study. According to Cassidy (2002), ${ }^{15}$ depression was found in $11.5 \%$ cases unlike in our study where depression was present in $81 \%$ cases with hypothyroidism.

\section{CONCLUSION}

Present study revealed importance of hormonal changes in PCOS, hypothyroidism and stress which causes psychophysical changes in young and reproductively active females. These hormonal changes along with modern lifestyle, less literacy in females, poor handling of pesticides, urbanisation are implicated in the suicidal attempt in young females. We, therefore, suggest the evaluation for PCOS and thyroid hormones in the young females in an attempt to intervene timely and perhaps prevent what could be an unforeseen disastrous implication like attempt to suicide.

\section{REFERENCES}

[1] Suicide prevention. WHO sites: Mental health. World Health Organization 2006.

[2] Shneidman ES. Basic words \& approaches. In: Definition of suicide. John Wiley \& sons, Canada 1985:3-23.

[3] O'Carroll PW, Berman AL, Maris RW, et al. Beyond the tower of babel: a nomenclature for suicidology. Suicide Life Threat Behav 1996;26(3):237-52.

[4] Retterslot N. Introduction and definitions. In: Suicide-a European perspective. $4^{\text {th }}$ edn. Cambridge: Cambridge University Press 1993:9-20.
[5] Hor K, Taylor M. Suicide and schizophrenia: a systematic review of rates and risk factors. J Psychopharmacol 2010;24(4 Suppl):81-90.

[6] Jain V, Singh H, Gupta SC, et al. A study of hopelessness, suicidal intent and depression in cases of attempted suicide. Indian $\mathrm{J}$ Psychiatry 1999;41(2):122-30.

[7] Narang RL, Mishra BP, Nitesh M. Attempted suicide in Ludhiana. Indian J Psychiatry 2000;42(1):83-7.

[8] Parkar SR, Nagarsekar B, Weiss MG. Explaining suicide in an urban slum of Mumbai, India: a sociocultural autopsy. Crisis 2009;30(4):192-201.

[9] Preti A, Miotto P. Social and economic influence on suicide: a study of the situation in Italy. Archives of Suicide Research 1999;5(2):141-56.

[10] Panda BB, Hansda MK, Mishra K, et al. Study of poisoning cases in an Indian tertiary care teaching hospital. JIAFM 2015;37(2):165-8.

[11] Farzaneh E, Mehrpour 0, Alfred S, et al. Self-poisoning suicide attempts among students in Tehran, Iran. Psychiatric Danubina 2010;22 (1):34-8.

[12] Benson S, Hahn S, Tan S, et al. Prevalence and implications of anxiety in polycystic ovary syndrome: results of an internet-based survey in Germany. Hum Reprod 2009;24(6):1446-51.

[13] Bartalena L, Pellegrini L, Meschi M, et al. Evaluation of thyroid function in patients with rapid-cycling and non-rapid-cycling bipolar disorder. Psychiatry Res 1990;34(1):13-7.

[14] Cassidy F, Ahearn EP, Carroll BJ. Thyroid function in mixed and pure manic episodes. Bipolar Disord 2002;4(6):393-7. 